\title{
Effects of Whole Body Vibration Therapy and Classic Physiotherapy on Postural Stability in People With Back Pain
} A Randomized Trial

\author{
Veronika Wegener, MD, * Stephanie Rarack, MD, *广 Theresa Tiffe, MSc, $\$$ Eva Grill, PhD, MPH, $\neq$ \\ Carolin Melcher, MD, ${ }^{*}$ Christof Birkenmaier, MD, ${ }^{*}$ Volkmar Jansson, MD, ${ }^{*}$ and Bernd Wegener, $M{ }^{*}$
}

\begin{abstract}
Study Design: This 2-step prospective randomized parallel trial evaluated postural stability in 65 back pain participants $(61.6 \pm 7.9$ y) and 50 nonback pain participants $(61.2 \pm 8.6 \mathrm{y})$ in a first step using the MFT-S3-Check. In a second step, postural stability and questionnaires were evaluated in back pain participants before and after therapy with either whole body vibration therapy or classic physiotherapy.
\end{abstract}

Objective: The first aim was to investigate whether the MFTS3-Check is suitable to evaluate differences in postural stability in back pain and nonback pain participants. The second aim was to evaluate the effect of whole body vibration therapy and classic physiotherapy on postural stability and the influence of depressive symptoms and pain.

Summary of Background Data: Objective bodily measurement values in chronic back pain are rare; therefore, the evaluation of effectiveness of different therapies is difficult.

Methods: Postural stability was investigated using stability-, sensorimotor-, and symmetry indexes, in standing and seated positions with the MFT-S3-Check. The following standard questionnaires were used to investigate pain and depressive symptoms: HADS, ODI, NASS, SF-36.

Results: No significant difference in postural stability was found between back pain participants and the nonback pain group. None of the two training concepts in back pain participants was superior,

Received for publication March 14, 2018; accepted November 26, 2018. From the *Department of Orthopaedics, Physical Medicine and Rehabilitation, University, Hospital, LMU Munich, Marchioninistraße; $\dagger$ MediCenter am Klinikum Bogenhausen, Englschalkinger Straße; \$nstitute for Medical Information Processing, Biometrics and Epidemiology, German Center for Vertigo and Balance Disorders, LMU Munich, Marchioninistraße, Munich; and §Institute of Clinical Epidemiology and Biometry (ICE-B), Julius Maximilian University of Würzburg, Petrinistraße, Würzburg, Germany.

V.W. and S.R. contributed equally.

Supported by Deutsche Arthrose-Hilfe e.V., a non-profit charity organization.

The authors declare no conflict of interest.

Reprints: Veronika Wegener, MD, Department of Orthopaedics, Physical Medicine and Rehabilitation, University, Hospital, LMU Munich, Campus Großhadern, Marchioninistraße 15, 81377 Munich, Germany (e-mail: Veronika.Wegener@med.uni-muenchen.de).

Copyright (C) 2019 Wolters Kluwer Health, Inc. All rights reserved. concerning postural stability and pain. Both treatments showed positive effects, with significant improvements in postural stability in the classic physiotherapy group. Depressive symptoms had a significant correlation with pain intensity in back pain participants.

Conclusions: The MFT-S3-Check could not find a significant difference in postural stability between the back pain and nonback pain group in the study setting. Postural stability improved after treatment.

Key Words: Nonspecific chronic back pain, postural stability, whole body vibration therapy, classic physiotherapy, MFT-S3-Check

(Clin Spine Surg 2019;32:E214-E220)

$\mathrm{N}$ onspecific chronic back pain is a common reason to seek medical advice and treatment, it causes high costs for treatment and for temporary or permanent disability. ${ }^{1}$ Multiple risk factors have been identified, ranging from educational and psychological status to working conditions and exposure to specific factors such as long term or high impact industrial vibration, whereas their specific contributions in individual cases are typically difficult to identify. ${ }^{1,2}$ In addition to psychological alterations, a decreased postural stability has been found in young nonspecific back pain patients. ${ }^{3}$ Acute muscle fatigue or pain may result in impaired back muscle function which is known to lead to an inability to adapt postural control strategies. ${ }^{4,5}$

Monitoring of unspecific back pain and changes in postural stability is difficult because of the rarity of specific monitoring systems available for broad use, and a poor comparability of the few measurable parameters. Most of the available body stability test systems use an unstable platform to measure movements to the sides, anterior and posterior, and around the center of rotation, such as the stabilometer platform or the MFT-S3-Check system (Trend Sport Trading $\mathrm{GmbH}$, Großhöflein, Austria). ${ }^{6,7}$ Artificial neuronal network techniques can differentiate postural sway patterns of several balance disorders using a stabilometer platform. ${ }^{8}$ In low back pain patients, reduced body balance was found when standing still, and by measuring the center of pressure on a 3-D force plate. ${ }^{9,10}$ 
One of the few validated test systems for balance and postural stability in healthy individuals is the MFT-S3-Check system, which is widely used in fitness and rehabilitative settings. ${ }^{6,10}$

Therapeutic interventions for treating back pain are diverse and may include multidisciplinary approaches. ${ }^{11}$ Classic physiotherapy (CPT) is capable of improving muscle performance, postural stability and pain. ${ }^{5,12}$ Devices for selftreatment at home are increasingly popular, but there is not sufficient evidence to support their therapeutic effect. Evans et $\mathrm{al}^{12}$ found that supervised exercise performed better than home exercise for chronic neck pain patients. Del Pozo-Cruz et $\mathrm{a}^{13}$ found an improvement of pain and postural stability index in nonspecific low back pain patients undergoing vibration board therapy versus the control group.

Whole body vibration therapy (WBVT) is gaining popularity and has been shown to be an effective training method to improve strength and postural stability. ${ }^{13-17}$ It has been shown to have a positive effect in fibromyalgia patients regarding pain and fatigue and in stroke patients regarding postural control and trunk stability. ${ }^{18-20}$ WBVT was shown to be effective in improving proprioception and postural stability in athletes with anterior cruciate ligament reconstruction. ${ }^{21}$ Elderly people may also benefit by improvement of balance and strength as well as of bone mineral density. WBVT may even be performed when an individual is too weak or staggering to participate in traditional training methods. ${ }^{22-25} \mathrm{In}$ nonspecific back pain, WBVT is considered a viable alternative to CPT, requiring less space, it is favored by Rittweger et al. ${ }^{26}$ Its safety aspects are widely discussed and depend on the vibration intensity, as well as on the duration of training sessions and on other factors. ${ }^{27}$ Different training platforms are in use in the fitness arenas with linear up and down or side altering vibration types. The Galileo therapy platform used in this study is a medical device with adjustable side altering vibration.

Other factors such as depression are known to have an influence on pain intensity as well as on the desire to move, ${ }^{28}$ but pain behavior was not related to anxiety or depression in Dickens' study in $2002 .{ }^{29}$ For psychological and quality of life monitoring and for the evaluation of pain, and especially back pain, questionnaires are available and widely in use. ${ }^{30}$ The SF-36-Score (Short Form 36 Health Survey), ${ }^{31}$ NASS-Score (North American Spine Society), ${ }^{32}$ Oswestry Disability Index (ODI) ${ }^{30}$ and Hospital Anxiety and Depression Scale $(\text { HADS })^{33}$ were chosen for this study.

The research questions were:

1. Is there a difference in postural stability between back pain and nonback pain participants?

2. Can whole-body vibration therapy (WBVT) and classic physiotherapy (CPT) improve postural stability in back pain participants?

3. Is there an influence of depressive symptoms on pain?

\section{MATERIALS AND METHODS}

\section{Design}

The first phase of this prospective, balanced randomized clinical study was a cross sectional assessment of differences in muscle-mediated spine stability in 65 back pain and 50 nonback pain participants using the MFTS3-Check by Trend Sport Trading GmbH, Großhöflein, Austria.

The second phase investigated postural stability before and after 2 matched training concepts (CPT and WBVT) within the group of back pain participants. Balanced randomization was performed by drawing lots. The influence of depressive aspects on back pain was evaluated using the relevant parts of the following questionnaires: HADS, ODI, NASS, SF-36.

\section{Participants, Therapists, Centers, Registration}

Participants with nonspecific chronic back pain were recruited from the Physical Medicine outpatient clinic. Participants without back pain were recruited by therapists and study conductors who invited relatives, friends, colleagues, and patients of other disciplines to take part in the study as control group. Personal data was anonymized by assigning 6-digit-numbers. Criteria for participants of the back pain group $[\mathrm{n}=65 ; 45$ female $(69.2 \%), 20$ male $(30.8 \%)$; mean age $61.6 \mathrm{y} \pm 7.9 \mathrm{SD}]$ and the nonback pain group $[\mathrm{n}=50 ; 20$ female $(40 \%), 30$ male $(60 \%)$; mean age 61.2 y $\pm 8.6 \mathrm{SD}]$ are as follows: age above 50 years, sporadic sports activities or physiotherapy, no neurologically verifiable disorder of coordination, no known history of diagnosed nausea or disorder of equilibrium.

Nonback pain participants have either never had back pain, or at least had no back pain with structural correlates in imaging during the last 3 years. They had to have normal muscular function.

Back pain participants had to show criteria for nonspecific chronic back pain, pain duration had to be $>3$ months; they had to have no muscular disorders and no known psychiatric secondary diagnoses.

The study was registered in the DRKS on February 02, 2017 under the number DRKS 00011305 post hoc.

\section{Ethics Approval}

The local University Ethics Committee approved this study. The study complies with the Declaration of Helsinki. Methods were carried out in accordance with the relevant guidelines and regulations. All participants gave written informed consent before data collection began.

\section{Interventions and Flow of Participants}

Initial assessment was performed in all 115 participants at time point $\mathrm{t} 0$, including medical history, a structured physical examination, measurement of postural stability, and four standardized questionnaires. One participant's data were excluded since he did not fill out the questionnaire completely.

Of 65 back pain participants in the first step, 44 could be recruited for the second study phase. In total, 21 participants were not available due to personal constraints or time management reasons. In the second phase, group 1 $(n=22)$ performed active CPT under the guidance of a physiotherapist twice a week for 3 blocks of 6 weeks each on level ground or partially on soft material with 

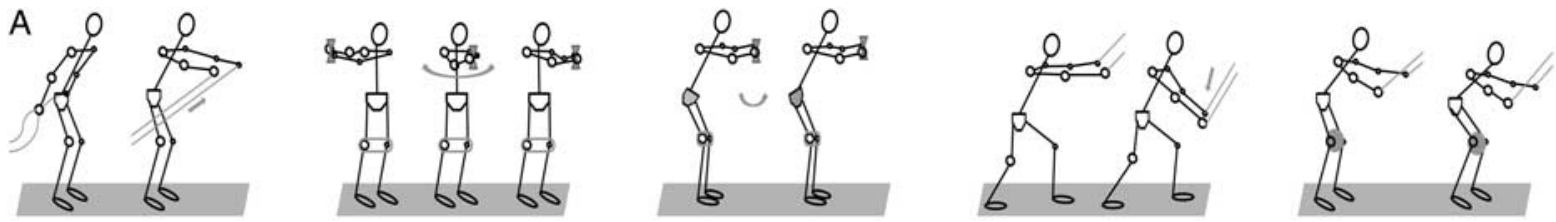

B
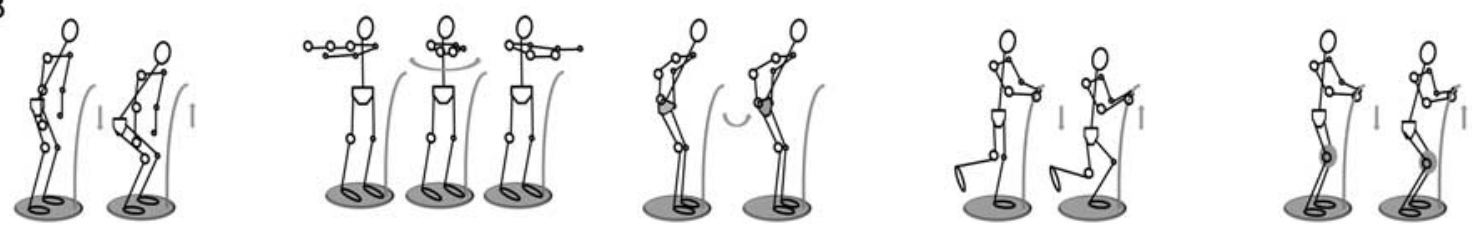

FIGURE 1. Matched exercises performed during classic physiotherapy (A) and whole body vibration therapy (B).

repetitions of 5 defined trunk stability exercises as shown in Figure 1. Weights of 3 to $6 \mathrm{~kg}$, theraband, ball and pulling wires were used. For each block of 6 weeks, referred to as level 1,2 , and 3 , training intensity was increased by increasing the weights.

Group $2(n=22)$ performed WBVT guided by a physiotherapist twice a week for 3 blocks of 6 weeks each on a Galileo plate (Novotec Medical GmbH, Pforzheim, Germany) with 5 defined exercises similar and matched to the first group for 1 to 2 minutes each, for increasing time and intensity at each block (at level 1 for 1 minute with a low intensity at a frequency of 5 to $12 \mathrm{~Hz}$, at level 2 for 1.5 minutes at a medium intensity of 12 to $20 \mathrm{~Hz}$, and at level 3 for 2 minutes at a high intensity of $20 \mathrm{~Hz}$ ).

During therapeutic intervention, 11 participants $(6$ in the CPT group and 5 in the WBVT group; 5 females, 6 males) quit training because of study-dependent and study-independent reasons; 33 participants were available for the final tests with the MFT-S3-Check; 38 participants, who took at least partially part in the interventions, filled out the final questionnaires within a maximum of 6 weeks after the 18 weeks of intervention.

Matched pairs (for time point t0 and time point $\mathrm{t} 1$ (18-24 wk after initial assessment) of 38 questionnaires (30 females and 8 males) and 33 MFT-S3-Check system value sets in standing and in seated position ( 25 females and 8 males) were evaluated.

\section{Outcome measures}

\section{Primary Outcome}

The MFT-S3-Check is an established system to measure balance and postural stability (by stability index - STI, sensorimotor index-SMI, and symmetry indexSI) in standing position (Fig. 2A). ${ }^{6}$

It includes a monoaxial balance platform with a standardized instability of $530 \mathrm{~mm}$ in diameter and a tilt angle of 12 degrees to both sides with an integrated sensor and related software to calculate indexes. measuring range $\pm 20 \mathrm{de}-$ grees, sampling rate $100 \mathrm{~Hz}$, accuracy of measurements 0.5
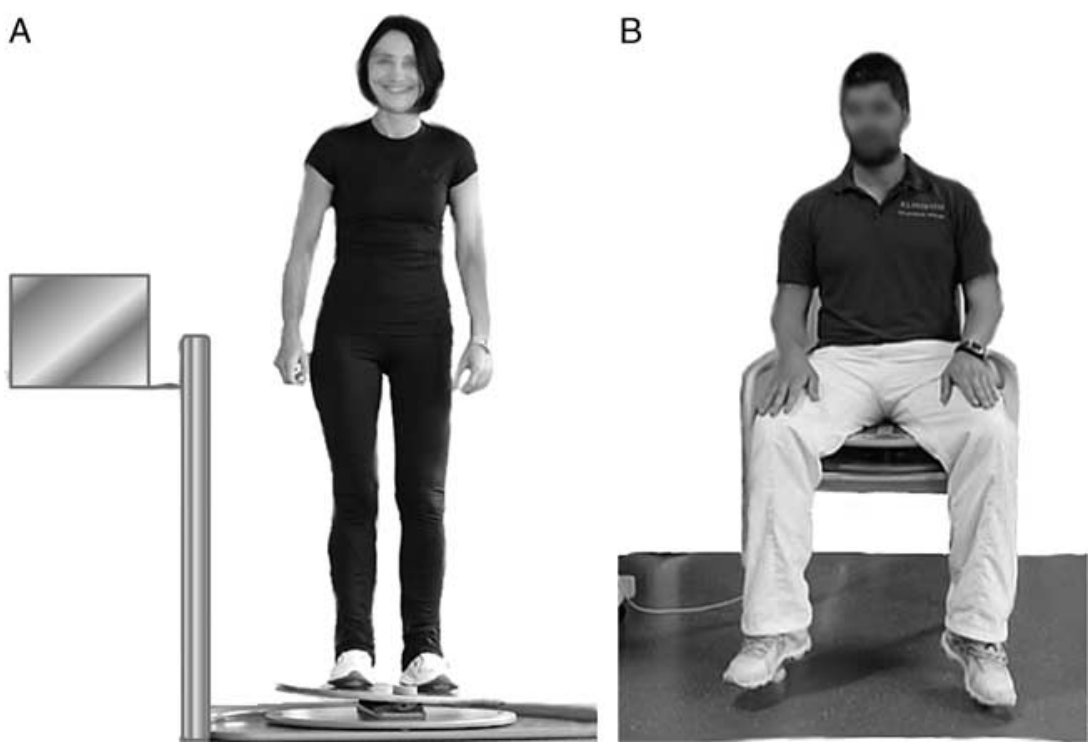

FIGURE 2. Test setting in standing (A) and seated (B) position on the MFT-S3-Check measuring plate performed by physiotherapists. 
degrees). Left-right standard measurement-sets were taken for 30 seconds after a short introduction, a warm up of 15 seconds and positioning for 5 seconds. Feet had to be placed parallel on markings, participants had to balance the platform as long and often as possible without laying hand on the handrail. After the first measurements participants were allowed for a break of 10 seconds and 5 seconds to find the right position again, then a second measurement-set was taken over another 30 seconds. The measurement-set with the higher quality was further evaluated.

The MFT-S3-Check was additionally modified by performing measurements in seated position (Fig. 2B) to assess the sensorimotor regulatory capacity and trunk stability independent of stabilization by the extremities (hip, knee, and ankle). The balance platform was placed on a specially designed wooden chair with the size of 50.5 $\mathrm{cm}$ in height, $55.5 \mathrm{~cm}$ in width, and $57.0 \mathrm{~cm}$ in depth.

Participants had to balance sitting freely with lower legs hanging down without contact to the floor and hands not having contact to the armrest.

\section{Parameters and Indexes}

Increased platform movement values during balancing imply a reduced postural stability of the test person. Compensation movements are necessary to retain balance. Measurements showing a small range of movements around the middle point indicate a good receptor activity, stimulus processing, and motor response in the test person.

The STI evaluates postural stability on an instable platform considering body symmetry and sensorimotor regulatory capacity on a scale from 1 (very good postural stability) to 9 (very poor postural stability).

The SMI evaluates the number and amplitude of compensation movements on a scale from 1 (very good sensorimotor performance with few and small compensation movements) to 9 (very poor sensorimotor performance with many and large movements). ${ }^{6}$

The SI evaluates deviation of movements to one side of the symmetrical plane during left-right measurements. The following 3 categories were assigned:

(1) $40: 60 \%$ up to $50: 50 \%$ : no preference of one side.

(2) $25: 75 \%$ to $39: 61 \%$ : slight preference of one side.

(3) $<24: 76 \%$ and $>76: 24 \%$ : distinct preference of one side.

\section{Questionnaires}

\section{Secondary Outcome:}

The SF- $36^{31}$ is a standard questionnaire assessing health related quality of life by 36 items in 8 sections: physical functioning, bodily pain, general health perceptions, vitality, physical role functioning, emotional role functioning, social role functioning, and mental health. It was established in the 1990s and was adjusted and improved over the years. On descriptive analysis, physical (subscale 1-4) and mental (subscale 5-8) component summary scores were evaluated in the current study. The subscale bodily pain was used as dependent variable in the generalized estimating equation (GEE) model analyzing depressive symptoms (HADS-depression).

The NASS lumbar was developed to measure diverse dimensions of the impact of lumbar spine problems, it was published in 1996. The currently used translation is configured for the lumbar module of the survey, which includes 16 items. ${ }^{32}$ Of these, two account for back pain, 6 for radiance of symptoms and 8 for dysfunctions during the previous 7 days. For descriptive analysis, the current study used the items for lumbar pain and lumbar neurology. The subscale lumbar pain was used to investigate the correlation of depressive symptoms in a GEE-model.

The ODI version 2.1., an index derived from the Oswestry Low Back Pain Questionnaire, quantifies pain and disability for low back pain participants in 10 sections. ${ }^{30}$

The HADS is commonly used for self-assessment of symptoms of anxiety and depression using 7 items each. ${ }^{33,34}$ We evaluated the 2 sections separately. Values of 9 or higher in the subsection HADS-depression were considered positive for depressive symptoms; the scale was dichotomized at a cut-off of 11 or larger, indicating prominent depressive symptoms.

\section{Statistical Analysis}

A sample size of 98 participants was calculated for the first phase, the cross sectional part of the study. Significance level was 0.05 , power was $95 \%$, $\alpha$ was 0.05 .

For the second phase, the sample size was only estimated since differences in parameters between the 2 interventions were not known prior and the number of participants needed to stay reasonable.

Analysis of data was performed using SPSS 21 (IBM Corp., Amonk). For descriptive analysis, mean, SD, and median were used to describe measurement values for continuous variables, as well as for absolute and relative frequencies of categorical variables. The Mann-Whitney $U$ test was used to test the null hypothesis of no difference between nonback pain group and back pain participants concerning the evaluated variables. A significant difference was assigned to $5 \%, P<0.05$. Data were considered to originate from explorative analysis; therefore, it was not adapted for multiple testing.

For analysis of the second phase of the study regarding pre- and post-interventional interpretation of training effects, the Wilcoxon test was used for dependent samples and the $U$ test for independent samples. Influence of age, sex and therapy modality was evaluated. The special form of regression model generalized estimation equations (GEE) was used to analyze longitudinal data and evaluated correlations of a primary variable and covariables over time.

\section{RESULTS}

\section{Research Question 1}

Comparing MFT-S3-Check values between nonback-pain group and back pain group, we found no significant difference in postural stability, neither in standing nor in seated position using the $U$ test for independent samples (Table 1). 
TABLE 1. Basic Data of Indexes for Nonback Pain and Back Pain Group

\begin{tabular}{|c|c|c|c|c|c|}
\hline \multirow[b]{2}{*}{ S3-Check Indices } & \multicolumn{2}{|c|}{ Nonback Pain } & \multicolumn{2}{|c|}{ Back Pain } & \multirow{2}{*}{$\frac{U \text { Test }}{P}$} \\
\hline & Mean & SD & Mean & SD & \\
\hline STI standing & 5.1 & $(1.0)$ & 5.0 & (1.3) & 0.68 \\
\hline STI seated & 3.6 & $(2.0)$ & 4.0 & (2.4) & 0.31 \\
\hline SMI standing & 4.1 & $(1.2)$ & 4.3 & (1.3) & 0.66 \\
\hline SMI seated & 2.9 & (1.7) & 3.4 & (2.3) & 0.33 \\
\hline SI standing right & 48.5 & (12.6) & 49.9 & $(9.7)$ & 0.80 \\
\hline SI standing left & 51.6 & (13.1) & 50.1 & $(9.7)$ & 0.85 \\
\hline SI seated right & 57.2 & $(16.2)$ & 50.7 & (15.4) & 0.07 \\
\hline SI seated left & 42.8 & $(16.2)$ & 49.3 & (15.4) & 0.07 \\
\hline
\end{tabular}

SI indicates symmetry index; SMI, sensorimotor index; STI, stability index.

The results showed slightly, but not significantly better postural stability values for both groups in the seated position.

\section{Research Question 2}

The effectiveness of the two interventions was evaluated regarding postural stability and pain. Significant improvements were seen in the CPT group regarding the STI ( 0.8 points) and the SMI (1.0 point) (Table 2$)$. In the WBVT group improvements were indicated, but not significant.

We found no significant changes in additional factors for back pain (anxiety, depression, lumbar pain, impairment) evaluated by the questionnaires in both groups over time. Values in the SF-36, NASS, ODI, HADS did not significantly change from to to $t 1$ for each intervention group.

The effectiveness of CPT and WBVT ( $U$ test applied on differences of index-values and questionnaires between time points) showed no significant superiority of one of them, except in the NASS neurologic symptoms subscale.
TABLE 3. Distribution of Depressive Symptoms in Study Participants

\begin{tabular}{lccc}
\hline Depression Symptoms & & & \\
HADS Score $\mathbf{\geq 9}$ & Per Group & \% of All & \% In Group \\
\hline Nonback pain group & $3 / 50$ & 2.6 & 6.0 \\
Back pain group & $11 / 65$ & 9.6 & 16.9 \\
All participants & $14 / 115$ & 12.2 & \\
\hline
\end{tabular}

\section{Research Question 3}

We found a prevalence of depressive symptoms in 14 $(12.2 \%)$ of 115 individuals at t0, $11(16.9 \%)$ in the back pain group, $3(6.0 \%)$ in the nonback pain group (Table 3 ).

We found no significant difference between treatments (CPT and WBVT) regarding the development of depressive symptoms over treatment time.

Depressive symptoms correlated with a significantly increased pain intensity (pain subscales of SF-36 $P=0.019$ and NASS $P=0.005$ ). Age, sex, and therapy modality showed no significance.

The STI was no significant variable on pain. The SMI showed a significant correlation with pain, measured by SF36 (standing and seated position $P=0.01$ ) and NASS (standing $P=0.03$ and seated $P=0.02$ ) in the GEE model. Poor SMI values correlated with a higher score for pain.

\section{DISCUSSION}

Literature describes reduced body balance or postural stability in back pain subjects compared to healthy individuals. ${ }^{3,4,9,10}$ In the current study the MFT-S3-Check system was not able to distinguish between back pain and nonback pain participants, neither in standing nor in seated position. There is a high variance in measurement values because of the

TABLE 2. Basic data of the Intervention Groups CPT and WBVT at t0 and t1

\begin{tabular}{|c|c|c|c|c|c|c|c|c|c|c|c|}
\hline \multirow{4}{*}{$\begin{array}{l}\text { Age Mean } \pm \text { SD }(y) \\
\text { Time }\end{array}$} & \multicolumn{5}{|c|}{ CPT } & \multicolumn{5}{|c|}{ WBVT } & \multirow{4}{*}{$\frac{U \text { Test }}{P}$} \\
\hline & \multicolumn{5}{|c|}{$63.9(6.5)$} & \multicolumn{5}{|c|}{$60.9(8.2)$} & \\
\hline & \multicolumn{2}{|c|}{ t0 } & \multicolumn{2}{|c|}{ t1 } & \multirow{2}{*}{$\frac{\mathrm{t0} \text { vs. } \mathrm{t1}}{P}$} & \multicolumn{2}{|c|}{ t0 } & \multicolumn{2}{|c|}{ t1 } & \multirow{2}{*}{$\frac{\overline{\mathrm{t0} \text { vs. } \mathrm{t1}}}{P}$} & \\
\hline & $\overline{\text { Mean }}$ & $\overline{(\mathrm{SD})}$ & Mean & $\overline{(\mathrm{SD})}$ & & Mean & $\overline{(S D)}$ & Mean & $\overline{(\mathrm{SD})}$ & & \\
\hline S3-Check indices & & & $\mathrm{n}=16$ & & & & & $\mathrm{n}=17$ & & & \\
\hline STI standing & 5.6 & $(1.5)$ & 4.8 & $(1.4)$ & 0.012 & 5.0 & $(1.0)$ & 4.4 & $(1.1)$ & 0.052 & 0.885 \\
\hline STI seated & 4.9 & (2.9) & 2.6 & $(2.3)$ & 0.015 & 3.9 & $(2.1)$ & 2.9 & $(2.4)$ & 0.073 & 0.516 \\
\hline SMI standing & 5.0 & $(1.5)$ & 4.0 & $(1.2)$ & 0.006 & 4.0 & $(1.2)$ & 3.4 & $(1.2)$ & 0.080 & 0.493 \\
\hline SMI seated & 4.1 & $(2.7)$ & 2.0 & $(1.8)$ & 0.004 & 2.9 & (1.9) & 2.0 & (1.6) & 0.065 & 0.217 \\
\hline SI standing right & 49.3 & $(7.5)$ & 50.8 & $(10.3)$ & 0.594 & 52.2 & $(13.0)$ & 47.8 & (14.4) & 0.245 & 0.718 \\
\hline SI standing left & 50.7 & $(7.5)$ & 49.3 & (10.3) & 0.594 & 47.8 & $(13.0)$ & 52.2 & (14.4) & 0.245 & 0.718 \\
\hline SI seated right & 55.5 & (15.1) & 54.1 & $(17.5)$ & 0.754 & 48.3 & $(22.0)$ & 51.7 & (21.9) & 0.865 & 0.773 \\
\hline SI seated left & 44.5 & (15.1) & 45.9 & (17.5) & 0.754 & 51.7 & $(22.0)$ & 48.3 & (21.9) & 0.865 & 0.773 \\
\hline Questionnaires & & & $\mathrm{n}=19$ & & & & & $\mathrm{n}=19$ & & & \\
\hline HADS/anxiety & 6.1 & (4.6) & 4.9 & $(3.2)$ & 0.364 & 5.2 & $(3.2)$ & 6.1 & (3.9) & 0.305 & 0.168 \\
\hline HADS/depression & 4.9 & $(3.4)$ & 4.4 & $(2.5)$ & 0.310 & 4.9 & $(2.6)$ & 5.3 & $(3.1)$ & 0.569 & 0.417 \\
\hline ODI & 20.7 & (11.4) & 16.6 & (12.3) & 0.185 & 18.1 & $(12.0)$ & 17.1 & (11.9) & 0.876 & 0.304 \\
\hline NASS/back pain & 2.9 & $(0.5)$ & 2.5 & $(0.8)$ & 0.085 & 2.6 & $(0.6)$ & 2.4 & $(0.7)$ & 0.195 & 0.520 \\
\hline NASS/neurol. symptoms & 2.5 & $(1.2)$ & 2.1 & $(1.0)$ & 0.068 & 2.0 & $(1.0)$ & 2.2 & $(1.2)$ & 0.588 & 0.048 \\
\hline SF-36 physical summary & 39.5 & $(9.1)$ & 41.4 & $(8.3)$ & 0.126 & 37.9 & $(7.5)$ & 40.7 & $(8.2)$ & 0.085 & 0.759 \\
\hline SF-36 mental summary & 48.8 & $(12.7)$ & 49.6 & (11.2) & 0.520 & 48.4 & $(15.0)$ & 44.7 & (16.3) & 0.349 & 0.314 \\
\hline
\end{tabular}

Bold value indicates significance $P$ values.

CPT indicates classic physiotherapy; SI, symmetry index; SMI, sensorimotor index; STI, stability index; WBVT, whole body vibration therapy. 
challenging measuring procedure regarding coordination. ${ }^{6,7}$ Postural stability was slightly, but not significantly increased in the nonback pain group. It remains unclear, whether there really are no significant differences or whether the differences are too small to be distinguished by this test.

We found that CPT and WBVT lead to an increase in postural stability, with significant improvement in the CPT group. These findings are consistent with the literature. $5,12,35$ Interestingly we found no superiority of one of the two applied treatments regarding postural stability. Ritzmann et $\mathrm{al}^{16}$ supposed in 2013 that different training protocols, varying duration of exercises as well as incomparability of the exercises in literature may have led to non-superiority of one treatment. Knowing this, we put much effort into the detailed matching of the exercises of both groups and could - maybe because of that -still not show superiority of one of the treatments.

Literature widely postulates an improvement of strength, postural stability, and pain by WBVT or a combination of WBVT and classic exercises in elderly or back pain subjects, and also in healthy individuals. ${ }^{13,14,16,17,26} \mathrm{We}$ found slight, but not significant improvements in postural stability in the WBVT group, which may be because of the different vibration intensity protocols suggested and used for therapeutic interventions and for exercises in fitness settings.

A connection between depressive symptoms and pain is widely described in literature. ${ }^{28,36}$ The current study confirms these findings, participants with a positive depression score showed higher pain intensity at the pain specific subscales of the questionnaires (NASS and SF-36) at t0 and t1. It remains unclear whether the depression is the cause for enhanced pain sensation or whether the presence of pain increases depressive symptoms.

We confirm a higher rate of participants with depressive symptoms in the back pain group than in the control group. A sex-specific statistical evaluation could not be provided because of the limited number of study participants. The disparity of sexes with over $70 \%$ of subjects being female in the back pain group and only $40 \%$ females in the nonback-pain group may lead to the higher numbers of subjects with depression in the back pain group, especially when taking into account that literature describes a high risk for female back pain patients to experience anxiety and depressive symptoms. ${ }^{36}$ But this cannot be statistically evaluated with the limited number of participants.

Literature describes exercise therapy as an effective treatment of depression. ${ }^{37-39}$ The current study found no influence of the therapy modality on depressive symptoms. This may be because of the short duration of the exercise period of only 18 weeks.

\section{Limitations}

The number of participants is limited due to the complexity of the study, therefore a sex-specific evaluation was not reasonable.

\section{Clinical Messages}

The MFT-S3-Check system could not distinguish between back pain and nonback pain subjects in the study setting regarding postural stability. Postural stability improved significantly after CPT treatment in back pain participants. WBVT showed positive effects without a significant improvement. None of the 2 training concepts was superior. Depressive symptoms had a significant correlation with higher pain intensity in back pain participants.

The MFT-S3-Check is valuable for monitoring therapeutic effects on postural stability.

\section{ACKNOWLEDGMENT}

The Galileo platform was provided by Novotec Medical GmbH Pforzheim, Germany.

\section{REFERENCES}

1. Hoy D, Brooks P, Blyth F, et al. The Epidemiology of low back pain. Best Pract Res Clin Rheumatol. 2010;24:769-781.

2. Bakker EW, Verhagen AP, van Trijffel E, et al. Spinal mechanical load as a risk factor for low back pain: a systematic review of prospective cohort studies. Spine. 2009;34:E281-E293.

3. Claeys K, Brumagne S, Dankaerts W, et al. Decreased variability in postural control strategies in young people with non-specific low back pain is associated with altered proprioceptive reweighting. Eur $J$ Appl Physiol. 2011;111:115-123.

4. Johanson E, Brumagne S, Janssens L, et al. The effect of acute back muscle fatigue on postural control strategy in people with and without recurrent low back pain. Eur Spine J. 2011;20:2152-2159.

5. Mannion AF, Taimela S, Muntener M, et al. Active therapy for chronic low back pain part 1. Effects on back muscle activation, fatigability, and strength. Spine. 2001;26:897-908.

6. Raschner C, Lembert S, Platzer HP, et al. S3-Check-evaluation and generation of normal values of a test for balance ability and postural stability. Sportverletz Sportschaden. 2008;22:100-105.

7. Schniepp R, Wuehr M, Pradhan C, et al. Nonlinear variability of body sway in patients with phobic postural vertigo. Front Neurol. 2013;4:115.

8. Krafczyk S, Tietze S, Swoboda W, et al. Artificial neural network: a new diagnostic posturographic tool for disorders of stance. Clin Neurophysiol. 2006;117:1692-1698.

9. Mann L, Kleinpaul JF, Pereira Moro AR, et al. Effect of low back pain on postural stability in younger women: influence of visual deprivation. J Bodyw Mov Ther. 2010;14:361-366.

10. Tilscher H, Gruber D, Lembert S, et al. Effects of impairments at the movement apparatus on the result oft he S3-body stability test. Manuelle Medizin. 2007;45:409-414.

11. Pieber K, Herceg M, Csapo R, et al. Effects of a multidisciplinary programme on postural stability in patients with chronic recurrent low back pain: preliminary findings. Eur Spine J. 2016;25:1219-1225.

12. Evans R, Bronfort G, Schulz C, et al. Supervised exercise with and without spinal manipulation performs similarly and better than home exercise for chronic neck pain: a randomized controlled trial. Spine. 2012;37:903-914.

13. del Pozo-Cruz B, Hernandez Mocholi MA, Adsuar JC, et al. Effects of whole body vibration therapy on main outcome measures for chronic non-specific low back pain: a single-blind randomized controlled trial. J Rehabil Med. 2011;43:689-694.

14. Kemmler W, Stengel VS, Mayer S, et al. Effect of whole body vibration on the neuromuscular performance of females 65 years and older. One-year results of the controlled randomized ELVIS study. Z Gerontol Geriatr. 2010;43:125-132.

15. Piecha M, Juras G, Krol P, et al. The effect of a short-term and longterm whole-body vibration in healthy men upon the postural stability. PloS One. 2014;9:e88295.

16. Ritzmann R, Gollhofer A, Kramer A. The influence of vibration type, frequency, body position and additional load on the neuromuscular activity during whole body vibration. Eur J Appl Physiol. 2013;113:1-11.

17. Ritzmann R, Kramer A, Bernhardt S, et al. Whole body vibration training-improving balance control and muscle endurance. PloS One. 2014;9:e89905.

18. Alentorn-Geli E, Padilla J, Moras G, et al. Six weeks of whole-body vibration exercise improves pain and fatigue in women with fibromyalgia. J Altern Complement Med. 2008;14:975-981. 
19. Merkert J, Butz S, Nieczaj R, et al. Combined whole body vibration and balance training using Vibrosphere(R): improvement of trunk stability, muscle tone, and postural control in stroke patients during early geriatric rehabilitation. Zeitschrift fur Gerontologie und Geriatrie. 2011;44:256-261.

20. Olivares PR, Gusi N, Parraca JA, et al. Tilting Whole Body Vibration improves quality of life in women with fibromyalgia: a randomized controlled trial. J Altern Complement Med. 2011;17:723-728.

21. Moezy A, Olyaei G, Hadian M, et al. A comparative study of whole body vibration training and conventional training on knee proprioception and postural stability after anterior cruciate ligament reconstruction. Br J Sports Med. 2008;42:373-378.

22. Rogan S, de Bruin ED, Radlinger L, et al. Effects of whole-body vibration on proxies of muscle strength in old adults: a systematic review and meta-analysis on the role of physical capacity level. Eur Rev Aging Phys Act. 2015;12:12.

23. Rogan S, Hilfiker R, Herren K, et al. Effects of whole-body vibration on postural control in elderly: a systematic review and meta-analysis. BMC Geriatrics. 2011;11:72.

24. von Stengel S, Kemmler W, Engelke K, et al. Effect of whole-body vibration on neuromuscular performance and body composition for females 65 years and older: a randomized-controlled trial. Scand J Med Sports. 2012;22:119-127.

25. Von Stengel S, Kemmler W, Bebenek M, et al. Effects of whole-body vibration training on different devices on bone mineral density. Med Sci Sports Exerc. 2011;43:1071-1079.

26. Rittweger J, Just K, Kautzsch K, et al. Treatment of chronic lower back pain with lumbar extension and whole-body vibration exercise: a randomized controlled trial. Spine. 2002;27:1829-1834.

27. Cardinale M, Wakeling J. Whole body vibration exercise: are vibrations good for you? Br J Sports Med. 2005;39:585-589.

28. Antunes RS, de Macedo BG, Amaral Tda S, et al. Pain, kinesiophobia and quality of life in chronic low back pain and depression. Acta Ortop Bras. 2013;21:27-29.
29. Dickens C, Jayson M, Creed F. Psychological correlates of pain behavior in patients with chronic low back pain. Psychosomatics. 2002;43:42-48

30. Mannion AF, Junge A, Fairbank JC, et al. Development of a German version of the Oswestry Disability Index. Part 1: crosscultural adaptation, reliability, and validity. Eur Spine J. 2006;15: $55-65$.

31. Bullinger M. Assessment of health related quality of life with the SF36 Health Survey. Rehabilitation (Stuttg). 1996;35:XVII-XXVII; quiz XXVII-XXIX.

32. Schochat T, Rehberg W, von Kempis J, et al. The North American Spine Society Lumbar Spine Outcome Assessment Instrument: translation and psychometric analysis of the German version in rehabilitation patients with chronic back pain. $Z$ Rheumatol. 2000;59: 303-313.

33. Zigmond AS, Snaith RP. The hospital anxiety and depression scale. Acta Psychiatr Scand. 1983;67:361-370.

34. Herrmann C, Buss U, Lingen R, et al. The screening for anxiety and depression in routine medical care. Dtsch Med Wochenschr. 1994;119:1283-1286.

35. Tsao H, Galea MP, Hodges PW. Reorganization of the motor cortex is associated with postural control deficits in recurrent low back pain. Brain. 2008;131(Pt 8):2161-2171.

36. Sagheer MA, Khan MF, Sharif S. Association between chronic low back pain, anxiety and depression in patients at a tertiary care centre. J Pak Med Assoc. 2013;63:688-690.

37. Kelley GA, Kelley KS. Effects of exercise on depressive symptoms in adults with arthritis and other rheumatic disease: a systematic review of meta-analyses. BMC Musculoskelet Disord. 2014;15:121.

38. Schuch FB, Pinto SS, Bagatini NC, et al. Water-based exercise and quality of life in women: the role of depressive symptoms. Women Health. 2014;54:161-175.

39. Wang YY, Chang HY, Lin CY. Systematic review of yoga for depression and quality of sleep in the elderly. J Nurs. 2014;61:85-92. 